\title{
Synthesis of 3-O-Sulfated Disaccharide and Tetrasaccharide Standards of Heparan Sulfate
}

Vijay Manohar Dhurandhare ${ }^{1}$, Vijayakanth Pagadala ${ }^{2}$, Andreia Ferreira ${ }^{3,4}$, Louis De Muynck ${ }^{3}$, and Jian $\mathrm{Liu}^{1^{*}}$

1. Division of Chemical Biology and Medicinal Chemistry, Eshelman School of Pharmacy, University of North Carolina, Chapel Hill, North Carolina, USA.

2. Glycan Therapeutics, LLC, 617 Hutton Street, Raleigh, North Carolina, USA.

3. Department of Neuroscience, Janssen Research \& Development, Janssen Pharmaceutica N.V., Turnhoutseweg 30, B-2340 Beerse, Belgium.

4. VIB Center for Medical Biotechnology, Ghent, Belgium; Department of Biochemistry and Microbiology, Ghent University, Ghent, Belgium.

\section{Supporting Information}

Title

Page Number

Additional experimental methods and NMR assignments

S2-4

Supplementary Fig S1. Structural and purity analysis of Compound $\mathbf{1}$

S5

Supplementary Fig S2. HSQC spectrum of Compound $\mathbf{1}$

S6

Supplementary Fig S3. Structural and purity analysis of Compound 2

S7

Supplementary Fig S4. COSY and HSQC spectrum of Compound 2

S8

Supplementary Fig S5. Structural and purity analysis of Compound 3

S9

Supplementary Fig S6. COSY \& HSQC spectrum of Compound 3

S10

Supplementary Fig S7. Structural and purity analysis of Compound $\mathbf{4}$

S11

Supplementary Fig S8. HSQC and HSQC-TOCSY spectrum of Compound $4 \quad$ S12

Supplementary Fig S9. HPLC chromatograms of compound 2 in $0.1 \mathrm{M} \mathrm{NH}_{4} \mathrm{HCO}_{3}$ buffer over time

Supplementary Fig S10. HPLC chromatograms of compound 3 in $0.1 \mathrm{M} \mathrm{NH}_{4} \mathrm{HCO}_{3}$ buffer over time

S14

Supplementary Fig S11. HPLC chromatograms of compound $\mathbf{4}$ in $0.1 \mathrm{M} \mathrm{NH}_{4} \mathrm{HCO}_{3}$ buffer over time

S15

Supplementary Fig S12. HPLC chromatograms of DUA-GlcNS6S disaccharide with or without incubation in $0.1 \mathrm{M} \mathrm{NH}_{4} \mathrm{HCO}_{3}$ buffer for 48 hours

Supplementary Fig S13. Stability data of compound 1-4 before and after 4 months

S17 Supplementary Fig S14. Mechanism for the degradation reaction for compound $\mathbf{1}$ under basic conditions 


\section{General Procedure for the Depolymerization of Octasaccharide}

Oligosaccharide $5 \mathrm{mg} / \mathrm{mL}+50 \mathrm{mM} \mathrm{Na} 2 \mathrm{HPO}_{4} 2 \mathrm{~mL}$

H. lyases I $100 \mu \mathrm{L}+\mathrm{H}$. lyases II $30 \mu \mathrm{L}+\mathrm{H}$. lyases III $30 \mu \mathrm{L}$

Digestion of 8-mer using Heparin lyases I, II, III overnight at $37^{\circ} \mathrm{C}$. Product formation was confirmed by HPLC analysis using $232 \mathrm{~nm}$ absorbance. Dimer and tetramer was purified using $\mathrm{P}_{2}$ Bio gel gravity column and buffer ( $\left.0.1 \mathrm{M} \mathrm{NH}_{4} \mathrm{HCO}_{3}\right), 15$ drops/tube for $8 \mathrm{~h}$. In case of $\mathbf{1}, \mathbf{2 ,} 3$ and 4 purification was done by using QA $=25 \mathrm{mM} \mathrm{Na}_{2} \mathrm{HPO}_{4} \mathrm{pH} \mathrm{4}, \mathrm{QB}=25 \mathrm{mM} \mathrm{Na}_{2} \mathrm{HPO}_{4}+1 \mathrm{M} \mathrm{NaCl}$, $\mathrm{pH}$ 4). After purification $\mathrm{pH} \sim 3$ was adjusted using $0.1 \mathrm{M}$ formic acid for stability. Stability and quantitation of the compounds was measured by HPLC analysis. Compound 1, 2 and 4 were stable for $12-15$ weeks in $-80{ }^{\circ} \mathrm{C}$ at $\mathrm{pH}$ 3. NMR analysis solvent locked using $\mathrm{H}_{2} \mathrm{O}+\mathrm{D}_{2} \mathrm{O}$ solvent, few peaks are suppressed with $\mathrm{H}_{2} \mathrm{O}$.

Compound 1_AUA-GIcNAc6S-GlcA-GIcNS3S6S $(\alpha: \beta=0: 1)$

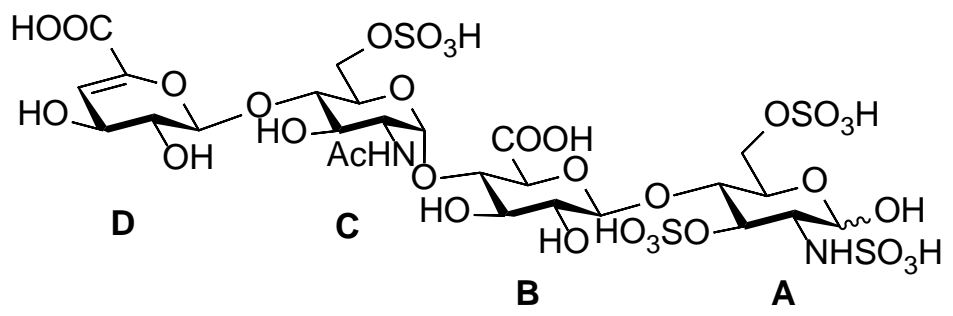

${ }^{1} \mathrm{H}$ NMR, (850 MHz H $\mathrm{H}_{2} \mathrm{O}+\mathrm{D}_{2} \mathrm{O}$ ) $\delta 5.85$ (d, $J=3.8 \mathrm{~Hz}, 1 \mathrm{H}, \mathrm{H}-4-\mathrm{D}$ ), 5.43 (d, $J=3.4 \mathrm{~Hz}, 1 \mathrm{H}, \mathrm{H}-1-$ A), 5.38 (d, $J=4.0$ Hz, 1H, H-1-C), 5.17 (d, $J=5.8$ Hz, 1H, H-1-D), 4.61 (m, 1H, H-1-B), 4.48 (t, $J=10.0$ Hz, 1H, H-3-A), 4.45-4.34 (m, 4H, H-6-A, H-6-C), 4.29 (dd, J = 11.4, 1.8 Hz, H-5-C), 4.23 (t, $J=4.5$ Hz, 1H, D-3), 4.22-4.20 (m, 1H, H-4-C), 4.20 (dd, $J=11.5,1.6$ Hz, 1H, H-5-A), 4.01 ( t, $J=10.0 \mathrm{~Hz}, 1 \mathrm{H}, \mathrm{B}-5$ ), 4.0 (t, $J=9.4 \mathrm{~Hz}, 1 \mathrm{H}, \mathrm{H}-4-\mathrm{A}$ ), 3.95 (dd, $J=10.8,3.9 \mathrm{~Hz}, 1 \mathrm{H}, \mathrm{H}-$ 2-C), 3.86-3.77 (m, 3H, H-4-B, H-3-C, H-2-D), 3.70 (td, $J=8.8,1.2$ Hz, 1H, H-3-B), 3.43 (dd, $J$ = 3.4, $1.06 \mathrm{~Hz}, 1 \mathrm{H}, \mathrm{H}-2-\mathrm{A}$ ), 3.37 (dd, $J=9.5,8.1 \mathrm{~Hz}, 1 \mathrm{H}, \mathrm{H}-2-\mathrm{B}) ; 2.12\left(\mathrm{~s}, 6 \mathrm{H}, \mathrm{CH}_{3} \alpha, \mathrm{CH}_{3} \beta\right) ;{ }^{13} \mathrm{C}$ NMR (212.5 MHz, $\left.\mathrm{D}_{2} \mathrm{O}\right) \delta$ 175.2, 174.7, 169.2, 144.8, 108.0, 101.2, 101.0, 97.14, 91.42, 77.12, 76.73, 76.54, 75.89, 73.61, 70.32, 69.07, 66.71, 66.08, 57.02, 53.49, 22.8; ESI-MS m/z [M-2H] ${ }^{2-}$ calculated for $\mathrm{C}_{26} \mathrm{H}_{40} \mathrm{~N}_{2} \mathrm{O}_{33} \mathrm{~S}_{4}$ 1036.83, found 517.1

Compound 2_AUA-GIcNS6S-GIcA-GIcNS3S6S ( $\alpha: \beta=1: 0)$ 


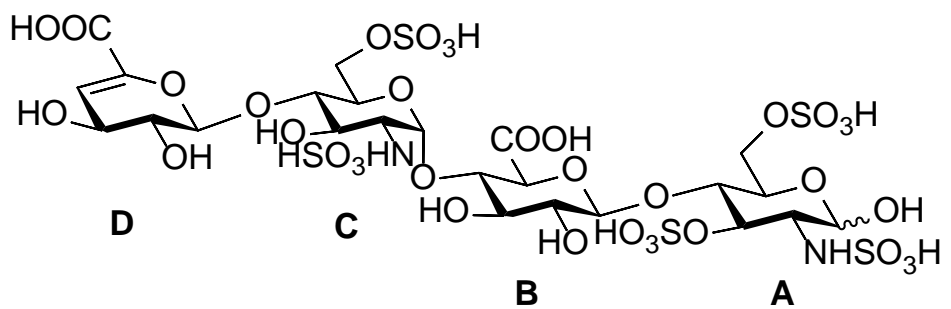

${ }^{1} \mathrm{H}$ NMR, (850 MHz D $\mathrm{O}$ ) $\delta 5.81$ (d, $J=3.5$ Hz, 1H, H-4-D), 5.64 (d, $J=3.8 \mathrm{~Hz}, 1 \mathrm{H}, \mathrm{H}-1-\mathrm{C}$ ), 5.46 (d, $J=3.3 \mathrm{~Hz}, 1 \mathrm{H}, \mathrm{H}-1-\mathrm{A}), 5.16$ (d, $J=6.4 \mathrm{~Hz}, 1 \mathrm{H}, \mathrm{H}-1-\mathrm{D}), 4.66$ (d, $J=7.90 \mathrm{~Hz}, 1 \mathrm{H}, \mathrm{H}-1-\mathrm{B}$ ), 4.50 (dd, $J=10.2,9.2$ Hz, 1H, H-3-A), 4.48 (dd, $J=11.2$, 1.6 Hz, 1H, H-6a-A), 4.45 (dd, $J=11.2$, 4.0 Hz, 1H, H-6a-C), 4.31 (dd, $J=11.2,2.2$ Hz, 1H, H-6b-C), 4.27 (dd, $J=5.8$, 3.6 Hz, 1H, H-3D), 4.24 (ddd, $J=9.6,3.6,2.1 \mathrm{~Hz}, 1 \mathrm{H}, \mathrm{H}-5-\mathrm{A}), 4.18$ (dd, $J=11.2,1.6,1 \mathrm{H}, \mathrm{H}-6 \mathrm{~b}-\mathrm{A}$ ), 4.04-4.01 (m, 2H, H-4-A, H-5-C), 3.90-3.83 (m, 3H, H-3, H-4, H-5-B), 3.80 (d, J = 6.0 Hz, 1H, H-4-C), 3.79 (d, $J=8.2$ Hz, 1H, H-2-D), 3.68 (dd, $J=10.4,9.2,1 \mathrm{H}, \mathrm{H}-3-\mathrm{C}$ ), 3.45 (dd, $J=10.4,3.4 \mathrm{~Hz}, 1 \mathrm{H}, \mathrm{H}-$ 2-A), 3.42 (dd, $J=9.0,8.2 \mathrm{~Hz}, 1 \mathrm{H}, \mathrm{H}-2-\mathrm{B}), 3.32$ (dd, $J=10.6,3.6 \mathrm{~Hz}, 1 \mathrm{H}, \mathrm{H}-2-\mathrm{C}$ ); ${ }^{13} \mathrm{C}$ NMR (212.5 MHz, $\left.\mathrm{D}_{2} \mathrm{O}\right) \delta 175.22,169.25,145.06,107.72,101.03,100.98,97.27,91.19,77.64,77.01$, 76.88, 76.19, 75.51, 73.26, 72.83, 70.55, 69.51, 69.15, 68.75, 67.08, 66.37, 65.84, 57.78, 56.96; ESI-MS m/z [M-2H] $]^{2-}$ calculated for $\mathrm{C}_{24} \mathrm{H}_{38} \mathrm{~N}_{2} \mathrm{O}_{35} \mathrm{~S}_{5}$ 1074.85, found 536.12

\section{Compound 3_AUA-GIcNS-IdoA2S-GIcNS3S}

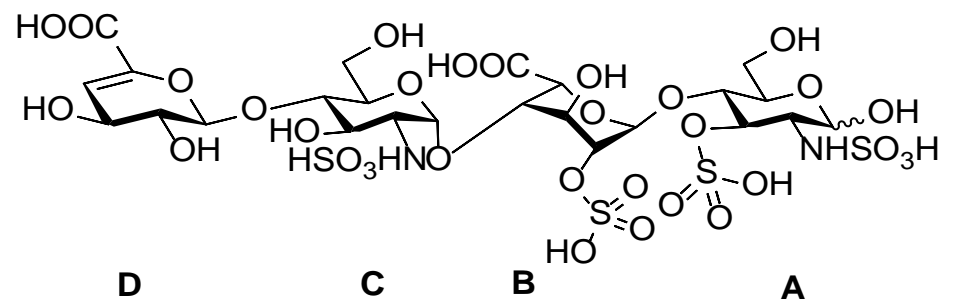

${ }^{1} \mathrm{H}$ NMR, (850 MHz D $\left.\mathrm{O}\right) \delta 5.75$ (d, $\left.J=3.2 \mathrm{~Hz}, 1 \mathrm{H}, \mathrm{H}-4-\mathrm{D}\right), 5.42$ (d, $J=3.2 \mathrm{~Hz}, 1 \mathrm{H}, \mathrm{H}-1-\mathrm{A} \alpha$ ), 5.40 (d, $J=3.3$ Hz, 1H, H-1-C), 5.19-5.18 (m, 1H, H-1-B), 5.04 (d, $J=6.8$ Hz, 1H, H-1-D), 4.884.85 (m, 1H, H-5-B), 4.66 (d, $J=7.8$ Hz, 1H, H-1-A $\beta$ ), 4.43 (t, $J=9.8$ Hz, 1H, H-3-C), 4.32-4.28 (m, 1H, H-3-A, H-2-B), 4.26 (dd, $J=6.0,3.3$ Hz, 1H, H-3-D), 4.13-4.11 (m, 2H, H-4-B, H-4-A), 3.97-3.90 (m, 4H, H6ab-A, H-3-B, H-4-C), 3.86-3.85 (m, 2H, H6ab-C), 3.80 (t, J = 9.3 Hz, 1H, H-5-C), 3.74 (t, $J=6.4$ Hz, 1H, H-2-D), 3.67 (t, $J=8.2$ Hz, 1H, H-3-A), 3.62-3.61 (m, 1H, H-3C), 3.40 (dd, $J=10.4,3.2$ Hz, 1H, H-2-C), 3.25 (dd, $J=10.4,3.2$ Hz, 1H, H-2-A), 3.23-3.21 (m, $1 \mathrm{H}, \mathrm{H}-2-\mathrm{A} \beta) ;{ }^{13} \mathrm{C}$ NMR (212.5 MHz, $\left.\mathrm{D}_{2} \mathrm{O}\right) \delta 145.07,107.77,100.98,96.00,91.34,77.46,76.19$, 
75.84, 75.33, 72.57, 71.36, 70.72, 70.63, 69.55, 69.46, 67.34, 59.62, 59.56, 57.87, 57.17; ESI-MS $\mathrm{m} / \mathrm{z}[\mathrm{M}-2 \mathrm{H}]^{2-}$ calculated for $\mathrm{C}_{24} \mathrm{H}_{38} \mathrm{~N}_{2} \mathrm{O}_{32} \mathrm{~S}_{4} 994.79$, found 496.2

\section{Compound 4_AUA2S-GIcNS3S6S}

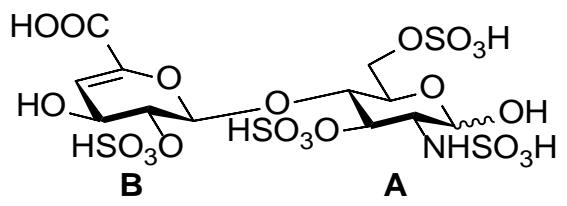

${ }^{1} \mathrm{H}$ NMR, (600 MHz H2O+D $\left.2 \mathrm{O}\right) \delta$ 6.06-6.05 (m, 1H, H-4-B), 5.51-5.49 (m, 1H, H-1-B), 5.35 (d, $J=3.40 \mathrm{~Hz}, 1 \mathrm{H}, \mathrm{H}-1-\mathrm{A}), 4.56$ (m, 1H, H-4-A), 4.37-4.28 (m, 1H, H-3-A), 4.27-422 (m, 2H, $\mathrm{CH}_{2}$, A-6), 4.16-4.14 (m, 2H, H-2-B, H-3-B), 4.07-4.04 (m, 1H, H-5-A), 3.40-3.38 (m, 1H, A-2); ${ }^{13} \mathrm{C}$ NMR $\left(150 \mathrm{MHz}, \mathrm{D}_{2} \mathrm{O}\right) \delta 168.5,144.3,105.6,95.75,91.60,74.75,73.14,73.01,69.03,66.37$, 61.81, 56.94; ESI-MS m/z [M-2H] ${ }^{2-}$ calculated for $\mathrm{C}_{12} \mathrm{H}_{19} \mathrm{NO}_{22} \mathrm{~S}_{4} 657.51$, found 327.6

$\Delta$ UA-GIcNS6S $(\alpha: \beta=10: 1)$

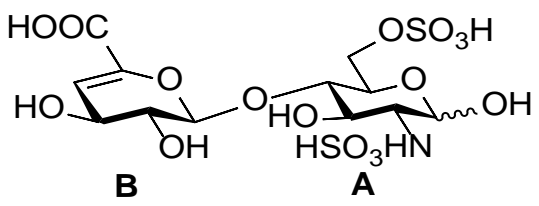

${ }^{1} \mathrm{H}$ NMR, (850 MHz D $\left.2 \mathrm{O}\right) \delta 5.87$ (d, $\left.J=3.8,1 \mathrm{H}, \mathrm{H}-4-\mathrm{B}\right), 5.48$ (d, $\left.J=3.5 \mathrm{~Hz}, 1 \mathrm{H}, \mathrm{H}-1 \mathrm{~A} \alpha\right), 5.22$ (d, $J=5.3 \mathrm{~Hz}, 1 \mathrm{H}, \mathrm{H}-1-\mathrm{B}), 4.76$ (d, $J=8.5 \mathrm{~Hz}, 1 \mathrm{H}, \mathrm{H}-1-\mathrm{A} \beta$ ), 4.76 (d, $J=8.5 \mathrm{~Hz}, 1 \mathrm{H}, \mathrm{H}-1 \mathrm{~A} \beta$ ), 4.38 (dd, $J=11.2,4.0 \mathrm{~Hz}, 1 \mathrm{H}, \mathrm{H6a}$ ), 4.32 (d, $J=3.0 \mathrm{~Hz}, 1 \mathrm{H}, \mathrm{NH}$ ), 4.26 (d, $J=11.0,2.0 \mathrm{~Hz}, 1 \mathrm{H}$, H6b), 4.22 (t, $J=4.3 \mathrm{~Hz}, 1 \mathrm{H}, \mathrm{H}-3 \mathrm{~B}$ ), 4.18-4.15 (m, 1H, H-5A), 3.85 (t, $J=5.2 \mathrm{~Hz}, 1 \mathrm{H}, \mathrm{H}-2 \mathrm{~B}$ ), 3.83 (d, $J=9.8 \mathrm{~Hz}, 1 \mathrm{H}, \mathrm{H}-4 \mathrm{~A}$ ), 3.74 (dd, $J=10.2,8.6 \mathrm{~Hz}, 1 \mathrm{H}, \mathrm{H}-3 \mathrm{~A}$ ), 3.30 (dd, $J=10.4,3.6 \mathrm{~Hz}$, 1H, H-2A) 3.07 (dd, $J=10.2,8.4 \mathrm{~Hz}, \mathrm{H}-2-\mathrm{A} \beta$ ); ${ }^{13} \mathrm{C}$ NMR $\left(212.5 \mathrm{MHz}, \mathrm{D}_{2} \mathrm{O}\right) \delta 144.2,107.6,100.3$, 100.0, 99.97, 95.53, 92.68, 90.97, 78.35, 72.25, 71.91, 68.80, 68.93, 67.67, 66.23, 66.15, 66.06, 57.56; ESI-MS m/z [M-H] ${ }^{1-}$ calculated for $\mathrm{C}_{12} \mathrm{H}_{19} \mathrm{NO}_{16} \mathrm{~S}_{2} 497.40$, found 496.0

$\triangle$ UA-GIcNAc6S $(\alpha: \beta=1: 1)$

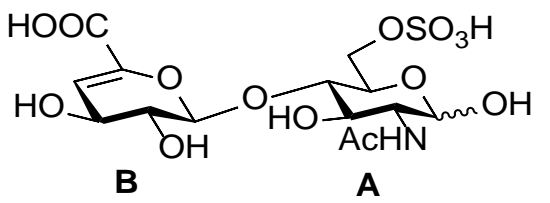


${ }^{1} \mathrm{H}$ NMR, (850 MHz D2O) $\delta$ 5.86-5.85 (m, 2H, H-4-B $\alpha, \mathrm{H}-4-\mathrm{B} \beta$ ), 5.23 (d, $J=3.4 \mathrm{~Hz}, 1 \mathrm{H}, \mathrm{H}-1-$ A $\alpha$ ), 5.22 (s, 1H, H-1B- $\alpha$ ), 5.21 (s, 1H, H-1B- $\beta$ ), 4.74 (d, $J=8.2$ Hz, 1H, H-1A- $\beta$ ), 4.38 (dd, $J=$ 11.2, 3.6 Hz, 1H, H-6aа), 4.33-4.32 (m, 2H, H6b), 4.26 (dd, $J=11.2,2.0$ Hz, 1H, H-6b $\beta$ ), 4.224.20 (m, 2H, H-3B $\alpha$, H-3B $\beta$ ), 4.18-4.16 (m, 1H, H-5-A $\beta$ ), 3.93-3.80 (m, 6H, H-A-2 $\alpha$, H-A3 $\alpha$, HA-4 $\alpha, \mathrm{H}-3-\mathrm{B}, \mathrm{H}-5 \alpha, \mathrm{H}-\mathrm{A} 3 \beta$ ), 3.71 (ddd, $J=18.0,10.4,7.8 \mathrm{~Hz}, 2 \mathrm{H}, \mathrm{H}-4 \mathrm{~b}, \mathrm{H}-2 \mathrm{~A} \beta$ ), 2.05 (s, 6H, $\left.\mathrm{CH}_{3}, \mathrm{CH}_{3}\right) ;{ }^{13} \mathrm{C}$ NMR $\left(212.5 \mathrm{MHz}, \mathrm{D}_{2} \mathrm{O}\right) \delta 174.4,144.6,107.45,107.40,100.56,100.50,100.41$, 95.03, 90.58, 90.51, 79.07, 78.61, 72.45, 72.13, 70.06, 70.01, 69.94, 69.08, 68.20, 68.14, 66.47, 66.40, 66.30, 66.24, 66.19, 56.32, 53.76, 22.11, 21.82; ESI-MS m/z $[\mathrm{M}-\mathrm{H}]^{-1}$ calculated for $\mathrm{C}_{14} \mathrm{H}_{21} \mathrm{NO}_{14} \mathrm{~S} 459.38$, found 458.2 
A

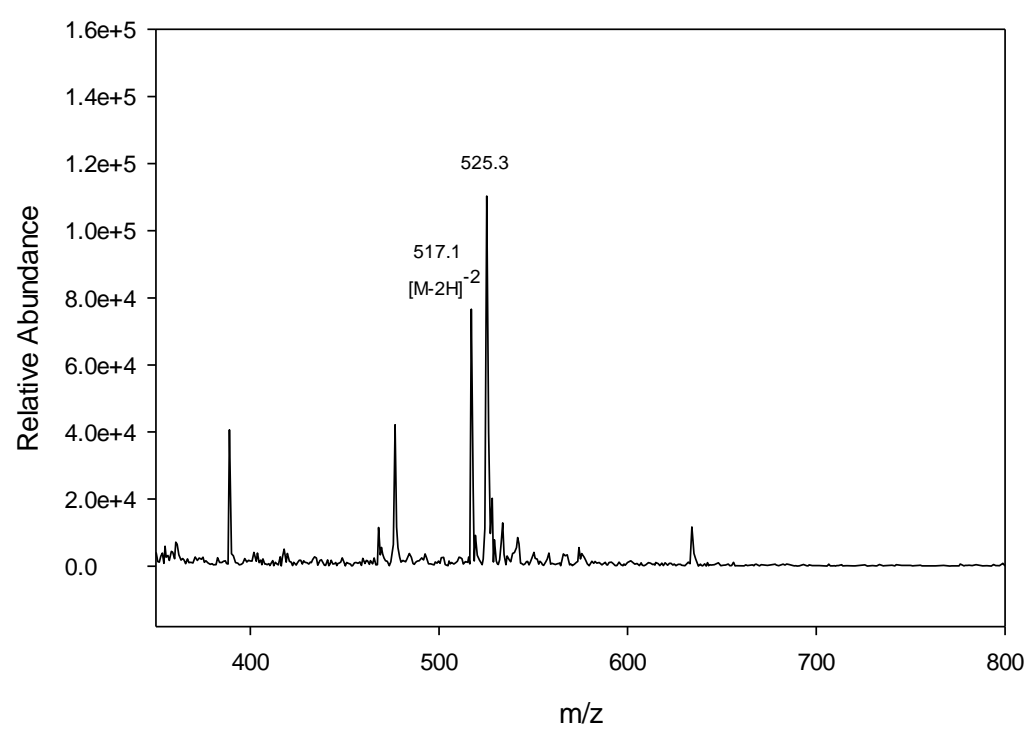

C

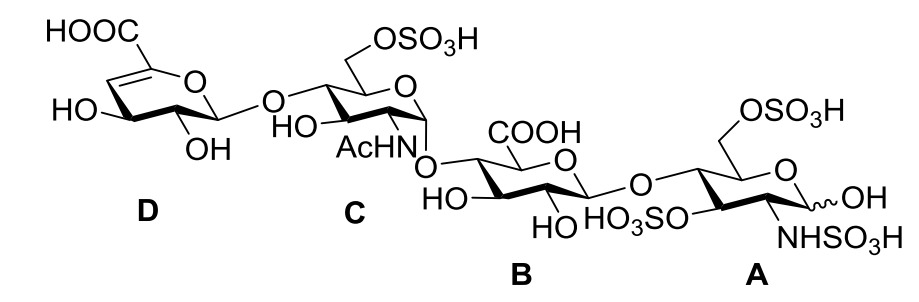

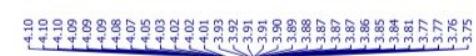

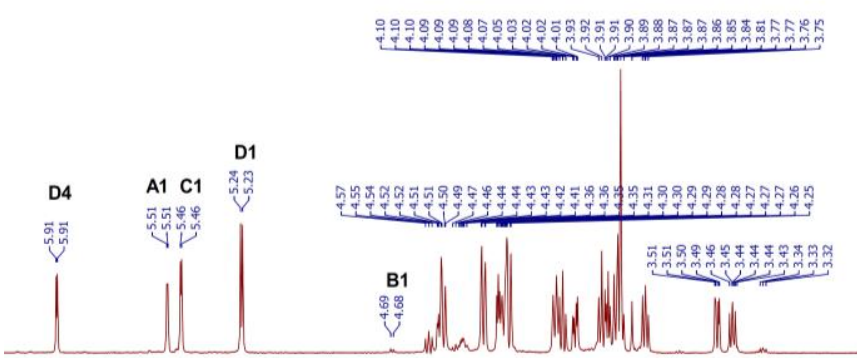

B

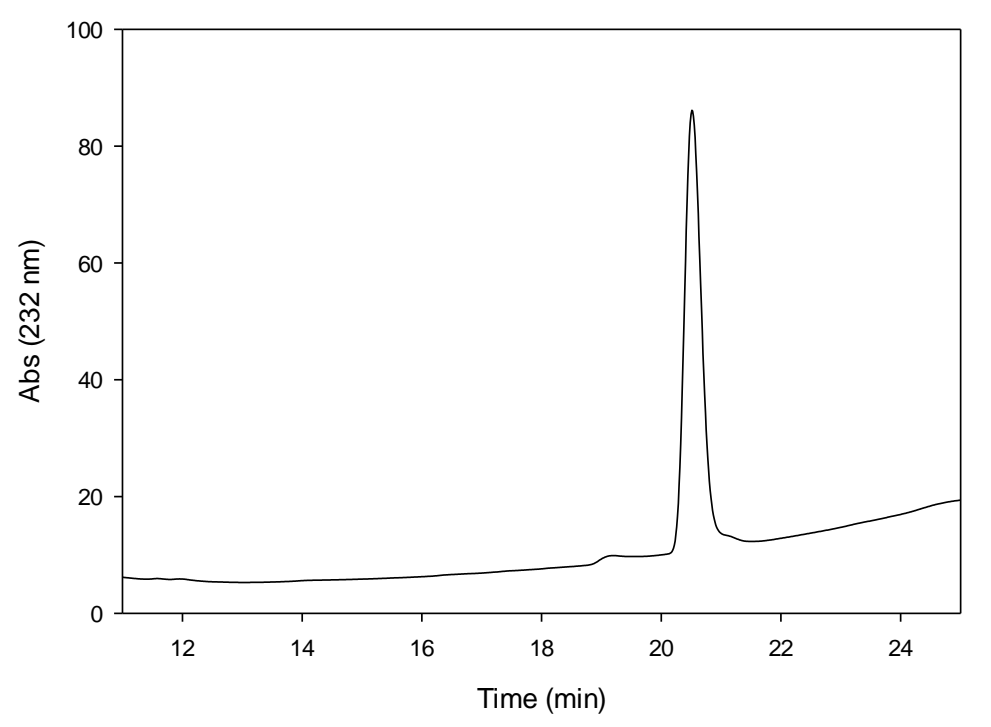

D
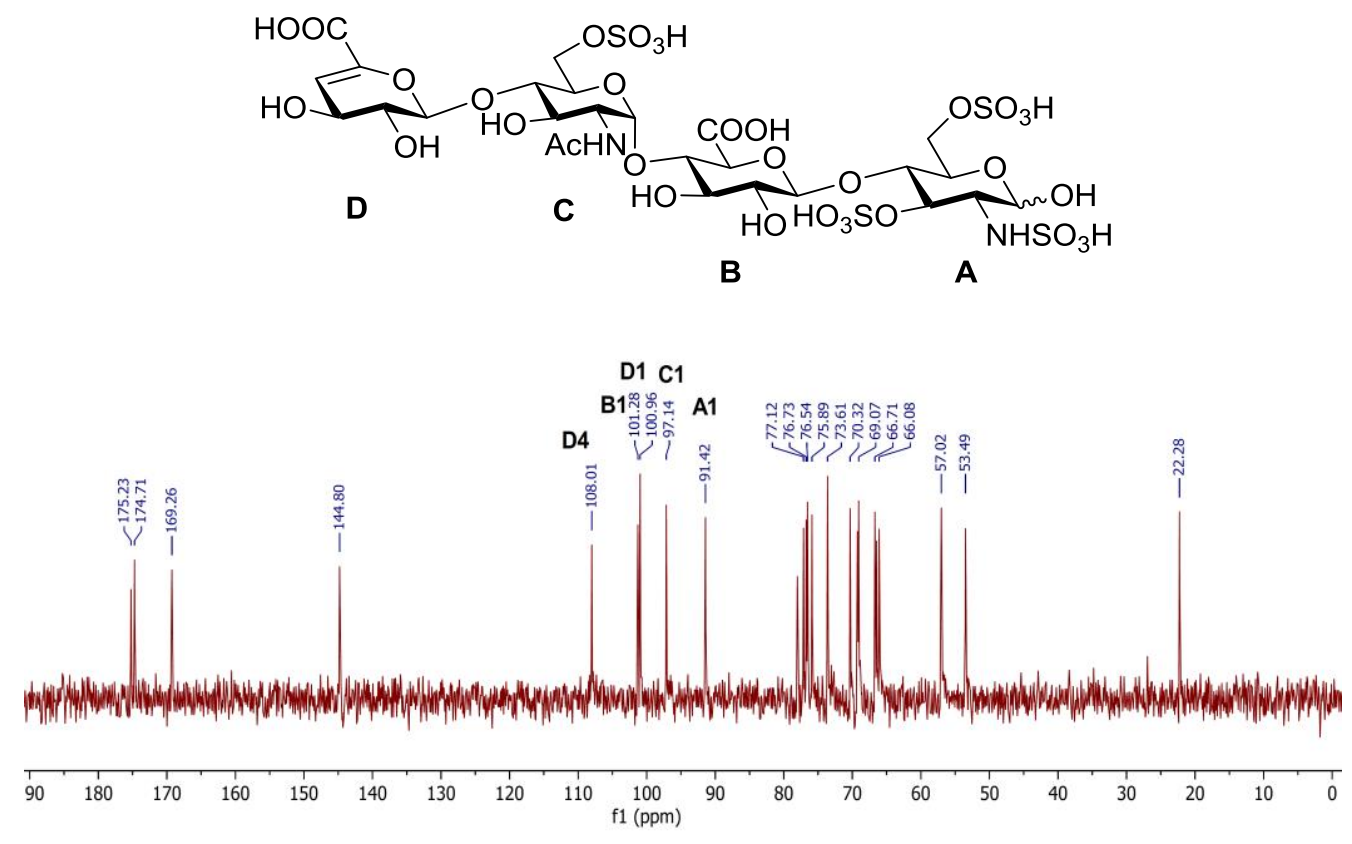


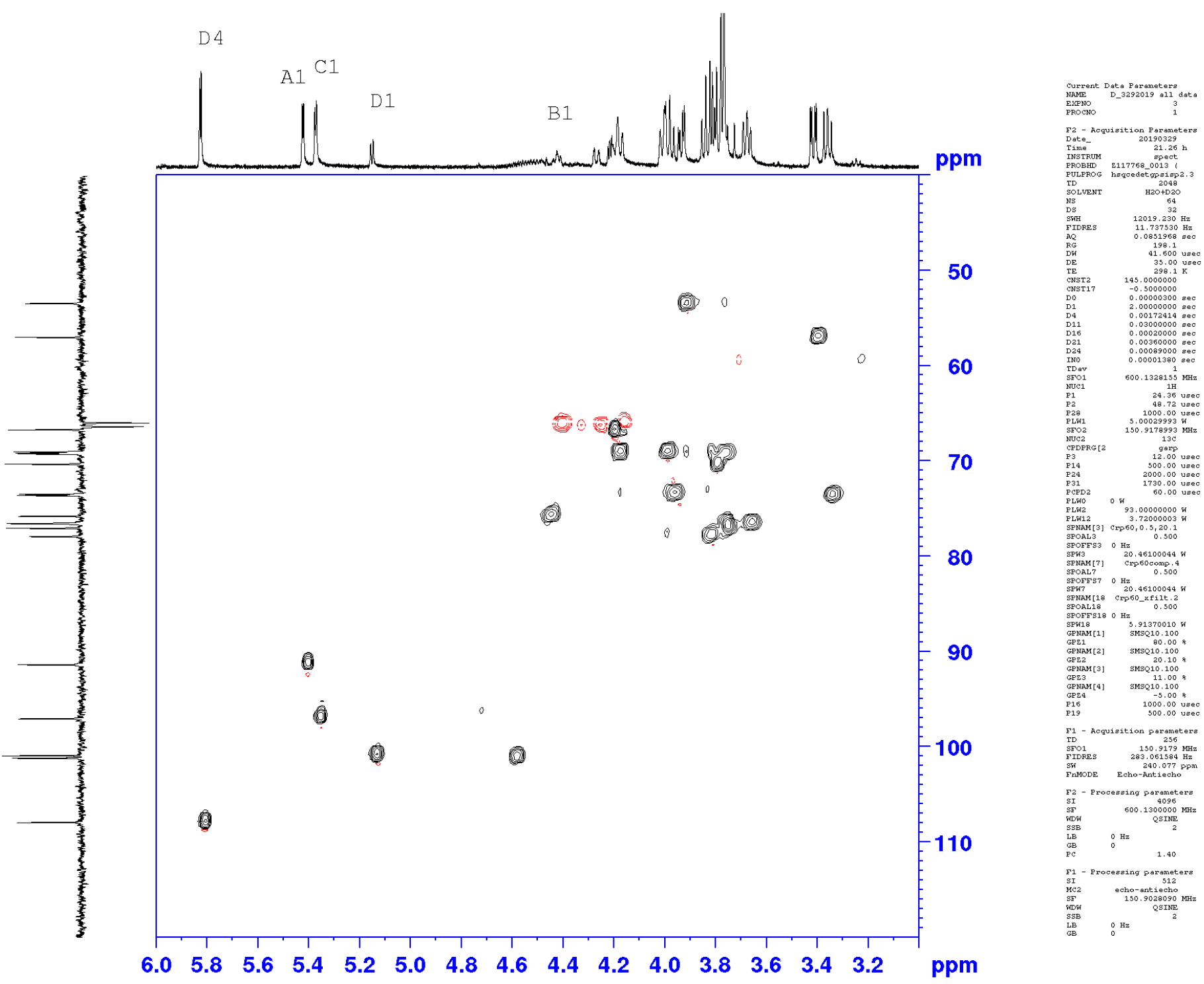

Supplementary Fig S2. HSQC spectrum of Compound 1 
A

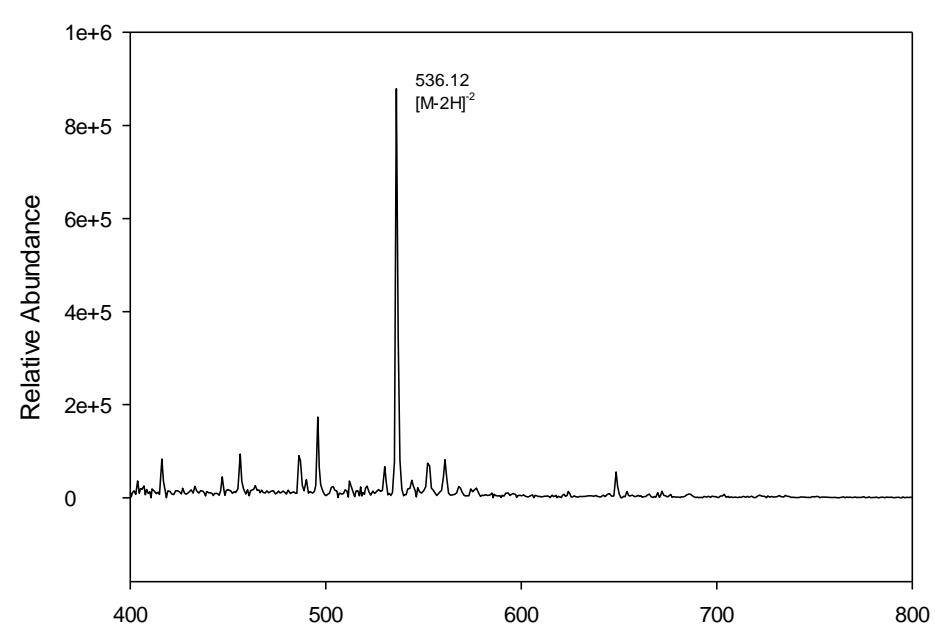

C

D4

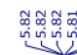

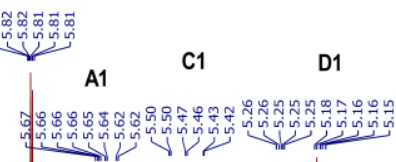

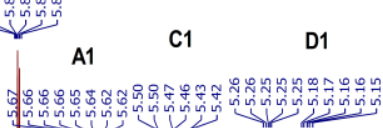

B1

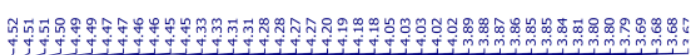

等

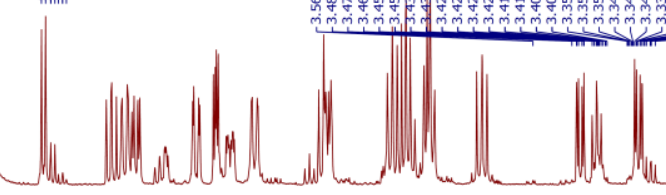

$\begin{array}{llllllllllllllll}6.0 & 5.9 & 5.8 & 5.7 & 5.6 & 5.5 & 5.4 & 5.3 & 5.2 & 5.1 & 5.0 & 4.9 & 4.8 & 4.7 & 4.6 & 4.5 \\ & & & & & & & & & & & & & & & \end{array}$
B

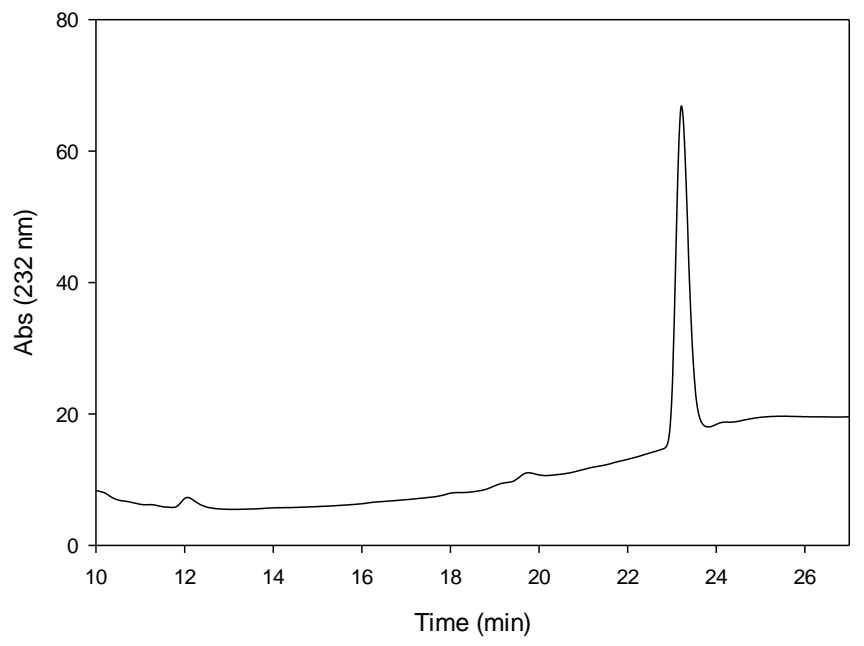

D

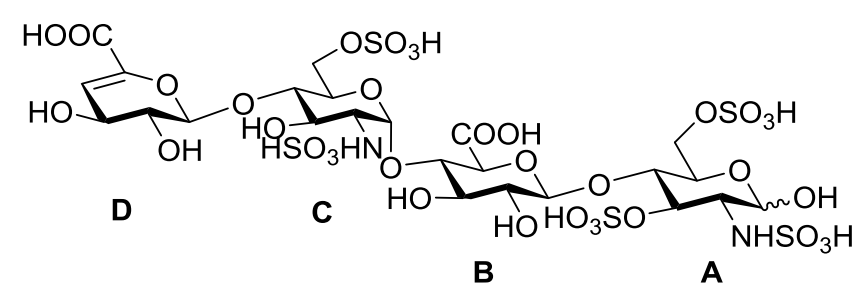

D1
B1

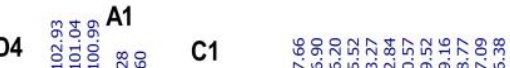

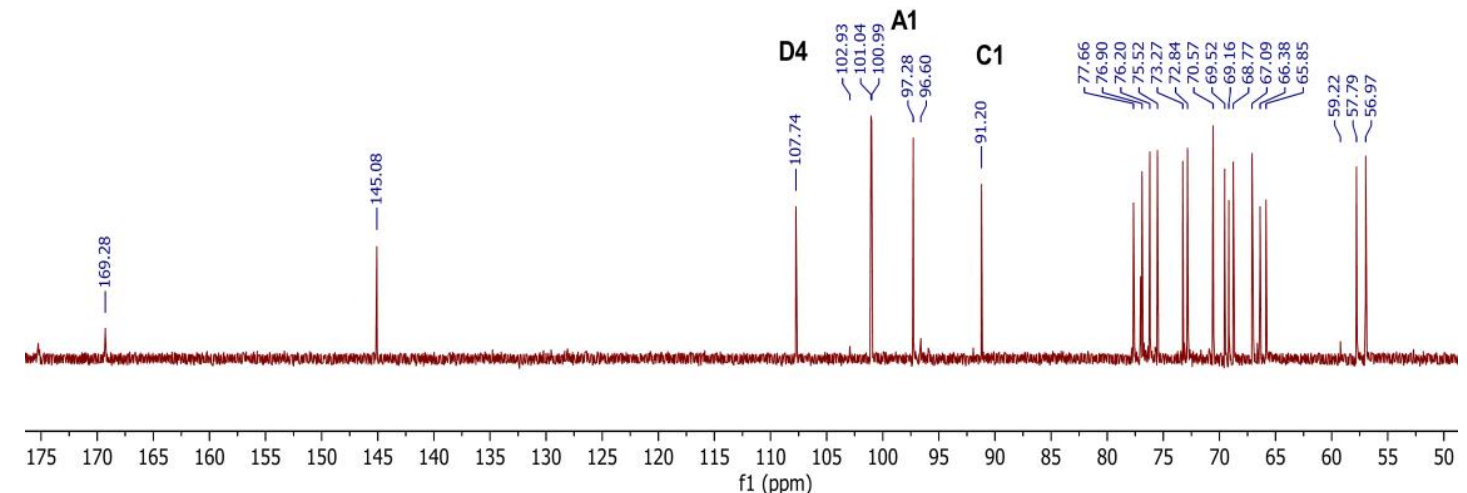

Supplementary Fig S3. Structural and purity analysis of Compound 2: (A) MS spectrum (B) HPLC Analysis (C) ${ }^{1} \mathrm{H}$ NMR Spectrum (D) ${ }^{13} \mathrm{C}$ NMR Spectrum 

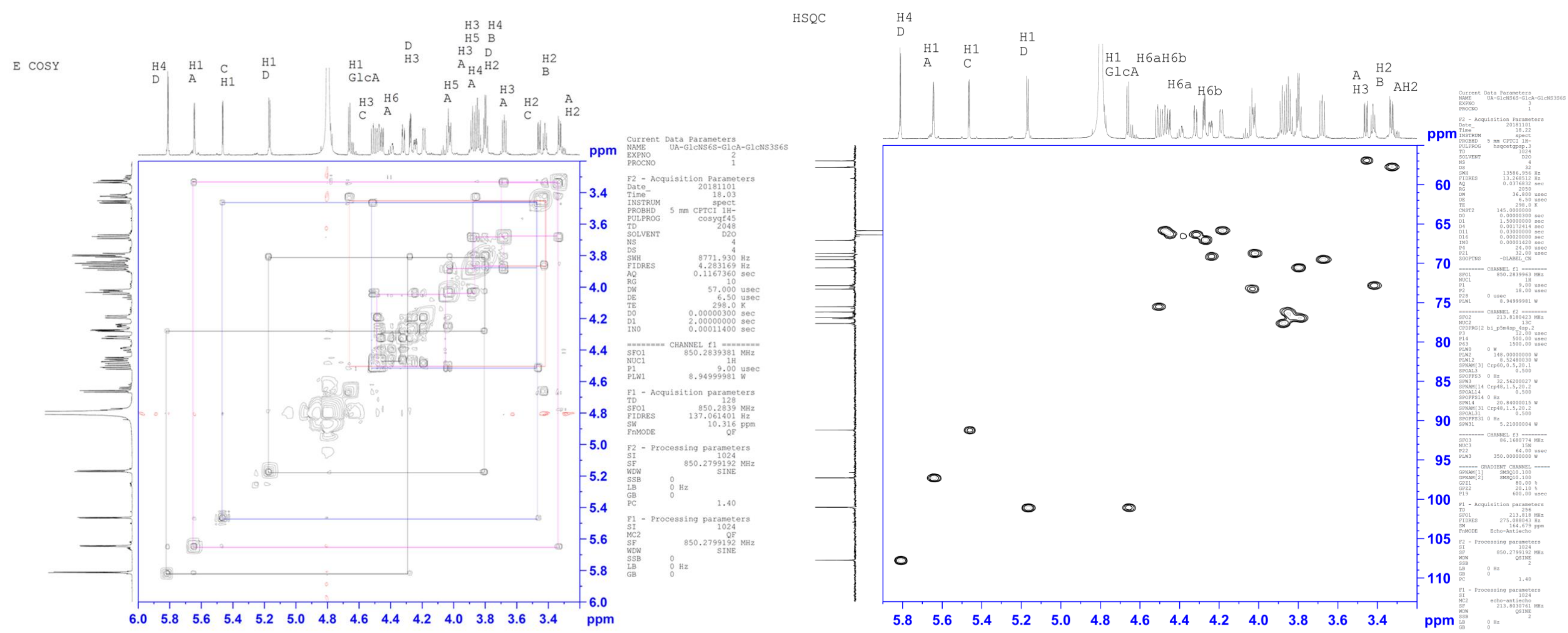

Supplementary Fig S4. COSY and HSQC spectrum of compound 2 
A

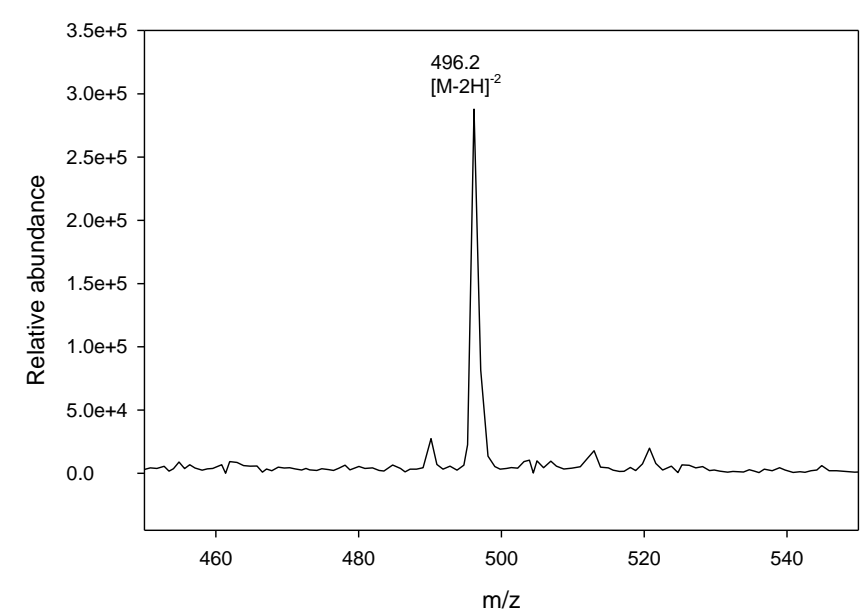

C

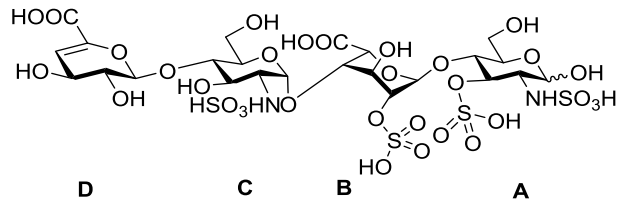

D1 $\mathrm{A} 1$

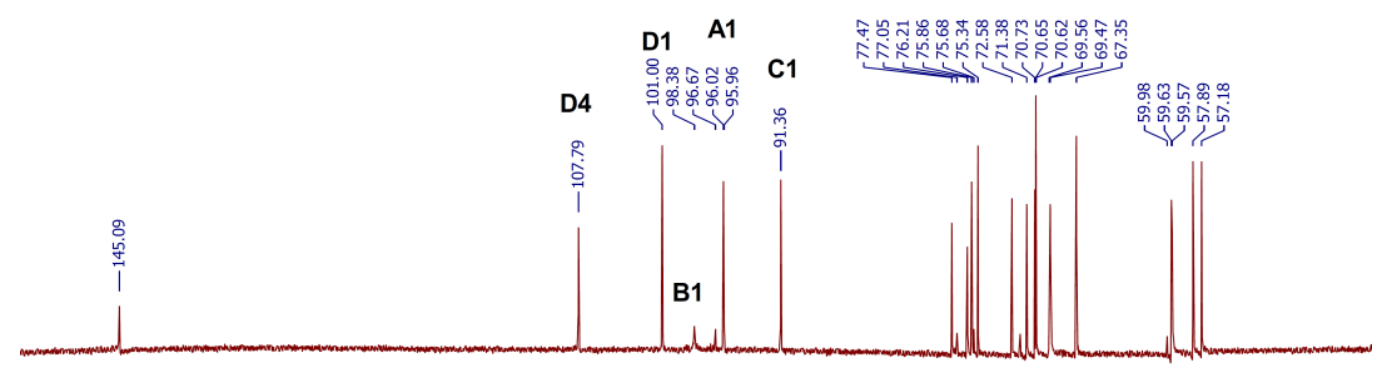

B

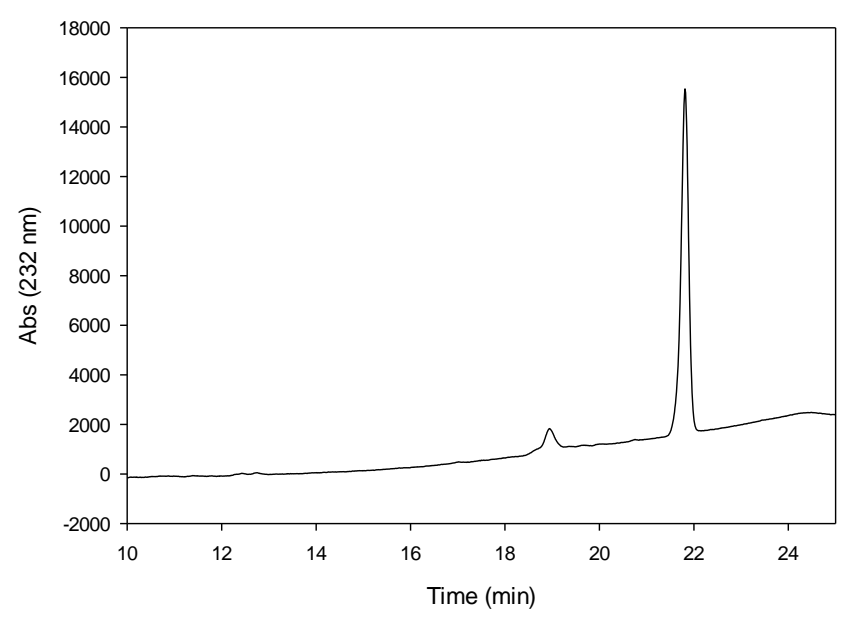

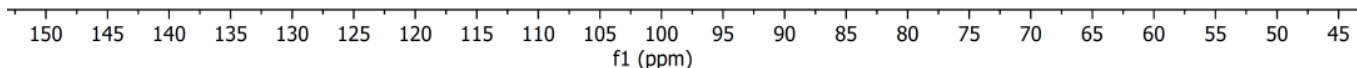

Supplementary Fig S5. Structural and purity analysis of Compound 3: (A) MS spectrum (B) HPLC Analysis (C) ${ }^{13}$ C NMR Spectrum 

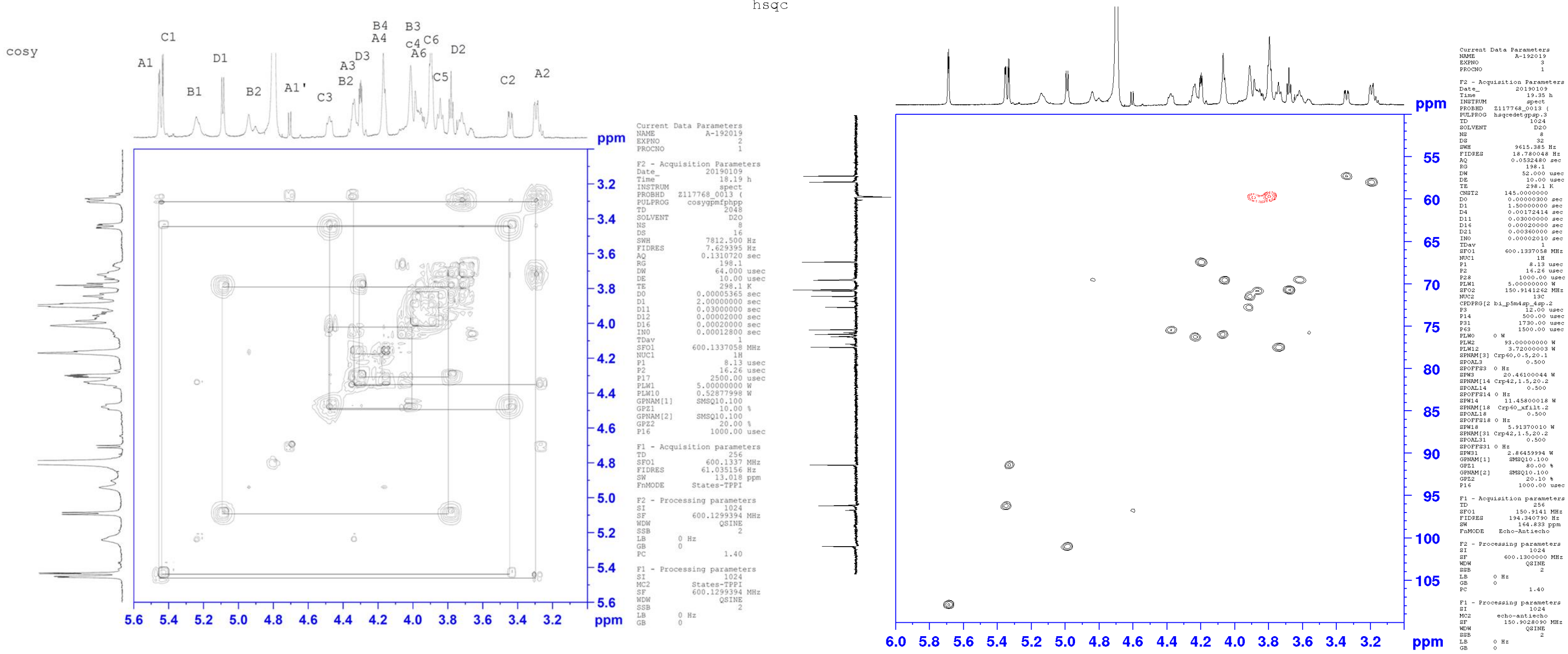

Supplementary Fig S6. COSY \& HSQC spectrum of compound 3 
A
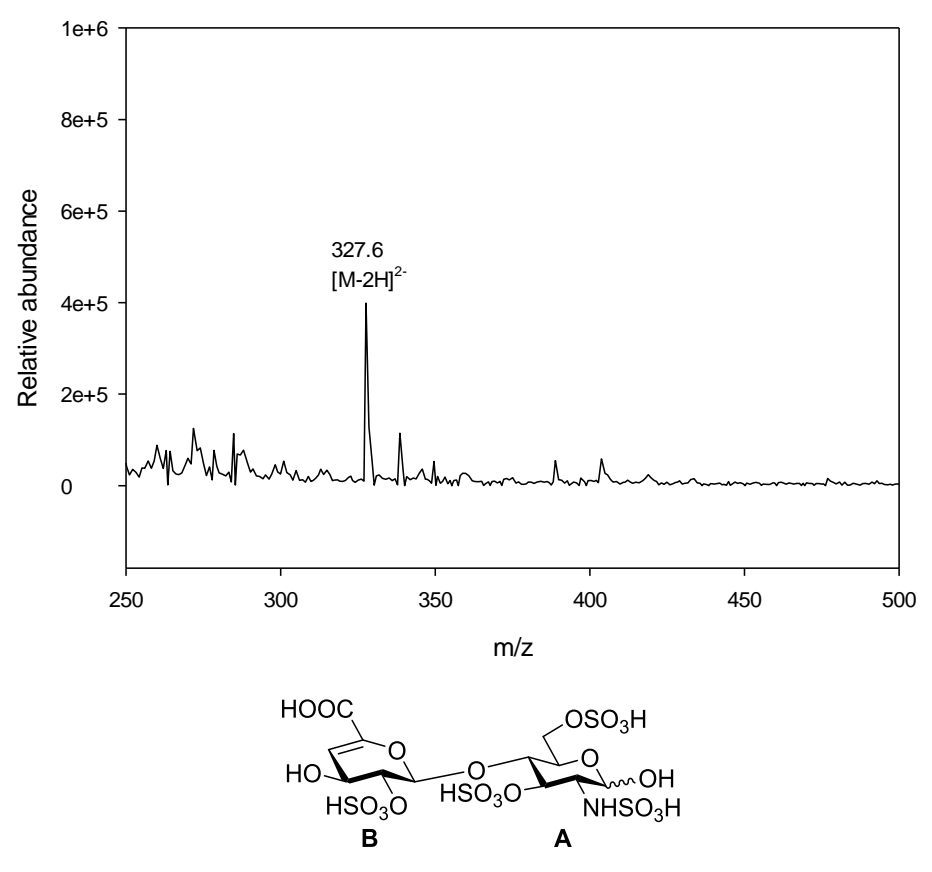

B

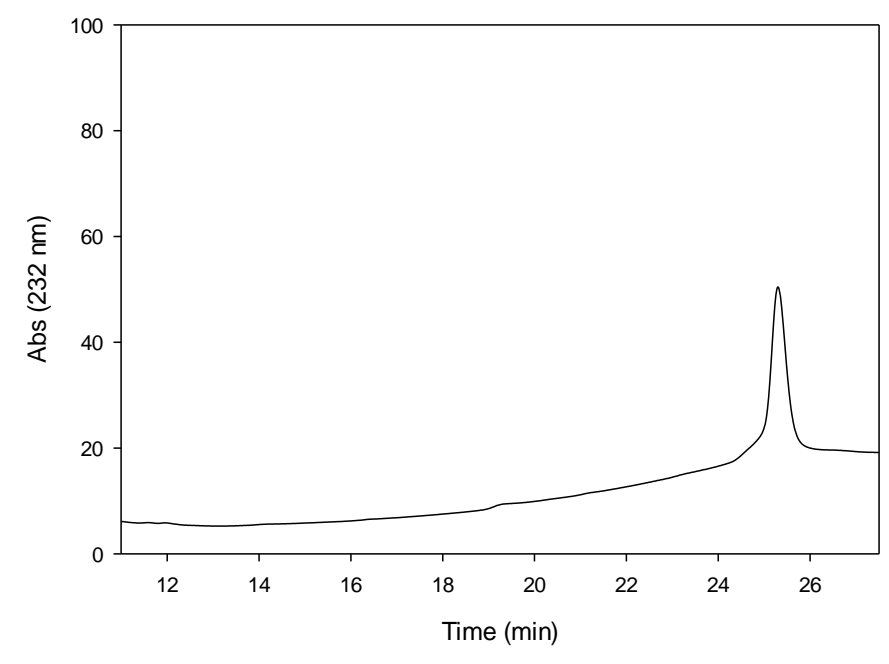

C

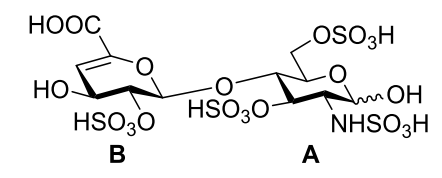

B4 B1 A

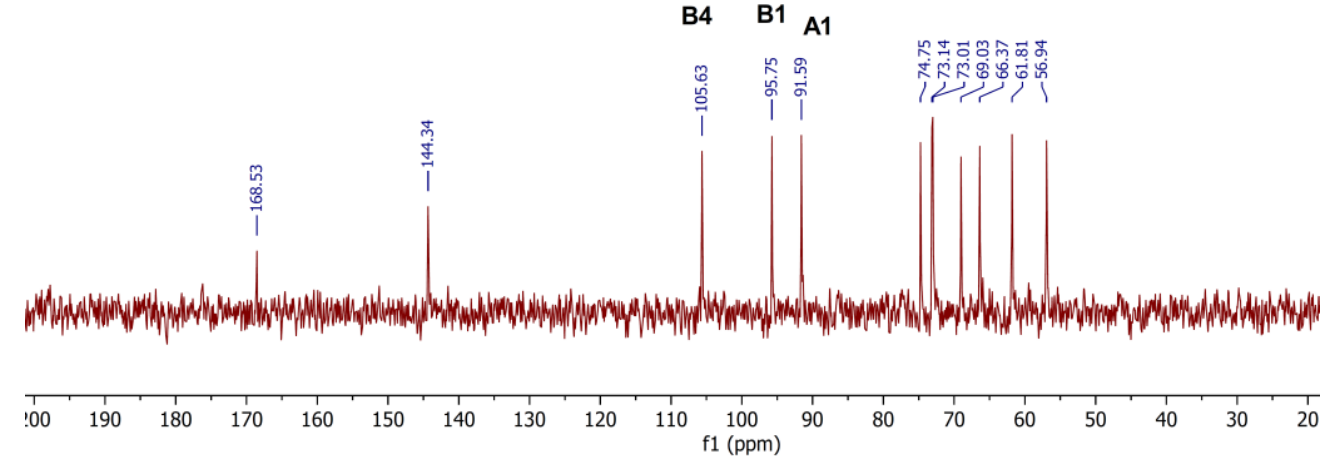




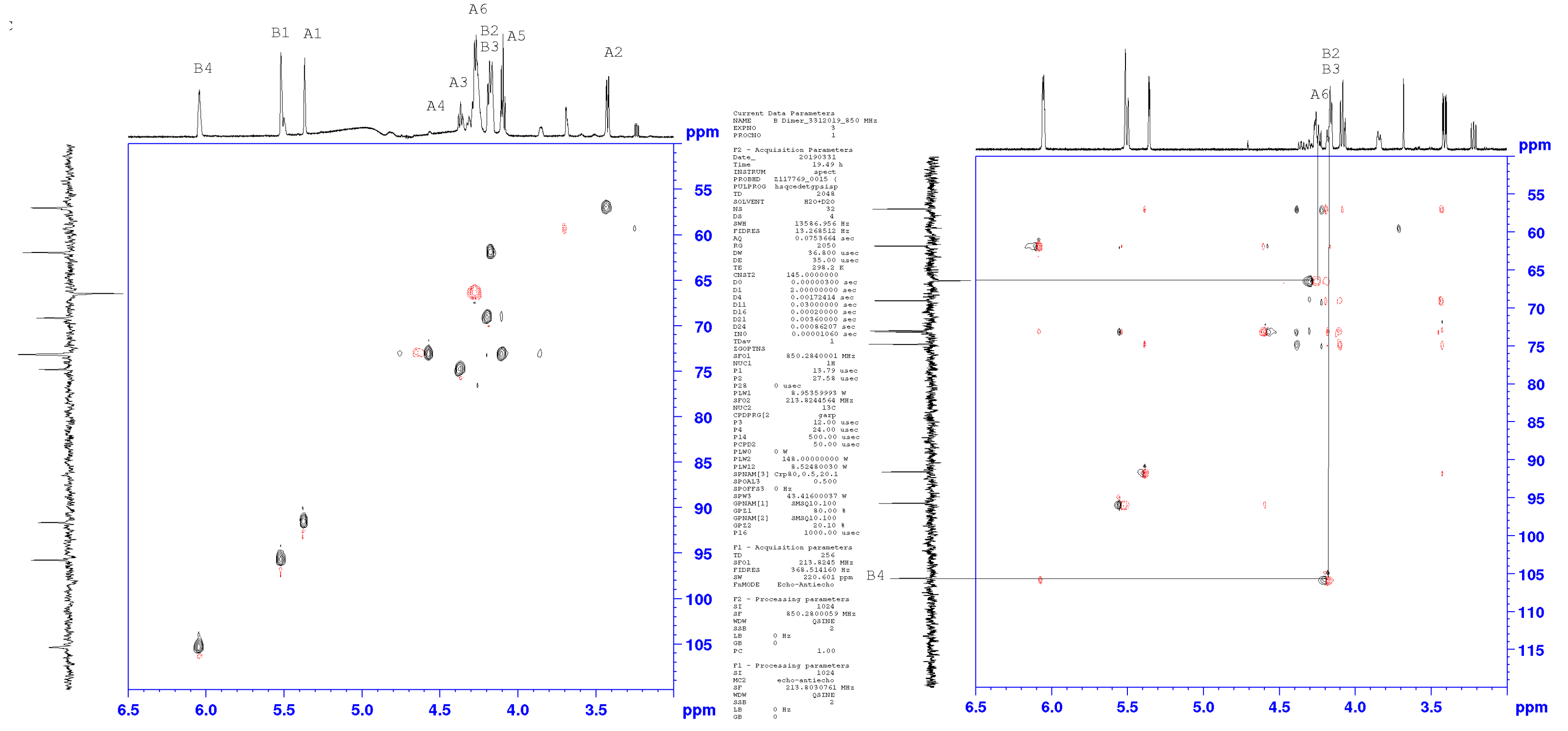

Supplementary Fig S8. HSQC and HSQC-TOCSY spectrum of Compound 4 

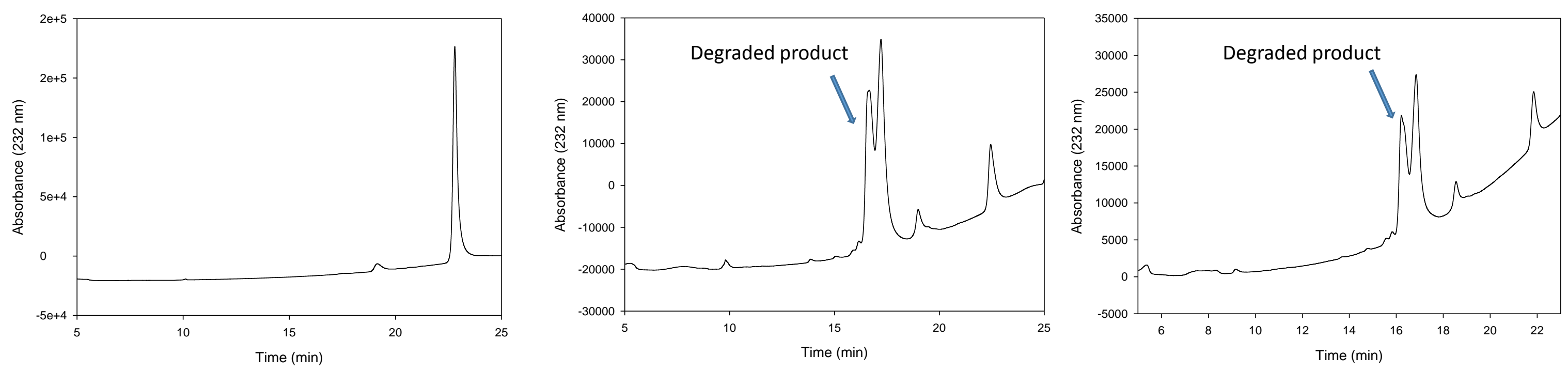

\section{Compound 2}

\section{$\Delta$ UA-GIcNS6S-GlcA-GIcNS3S6S}
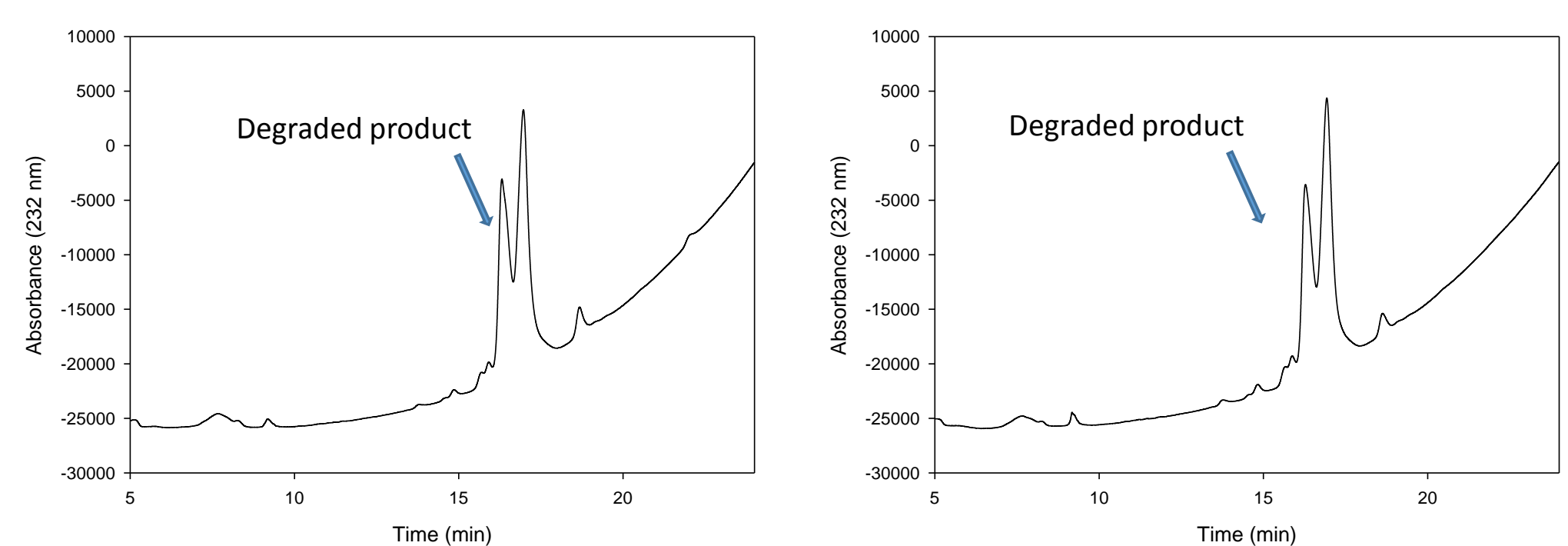

Supplementary Fig S9. HPLC chromatograms of compound 2 in $0.1 \mathrm{M} \mathrm{NH}_{4} \mathrm{HCO}_{3}$ buffer over time. 


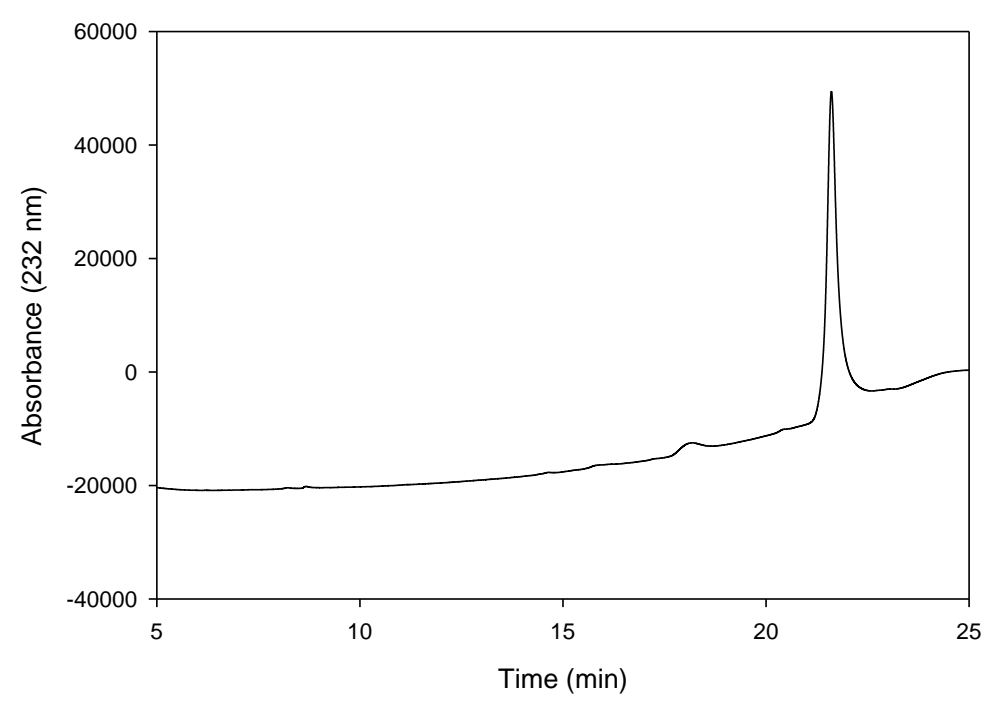

Compound $\mathbf{3}$

\section{$\Delta$ UA-GIcNS-IdoA2S-GIcNS3S}

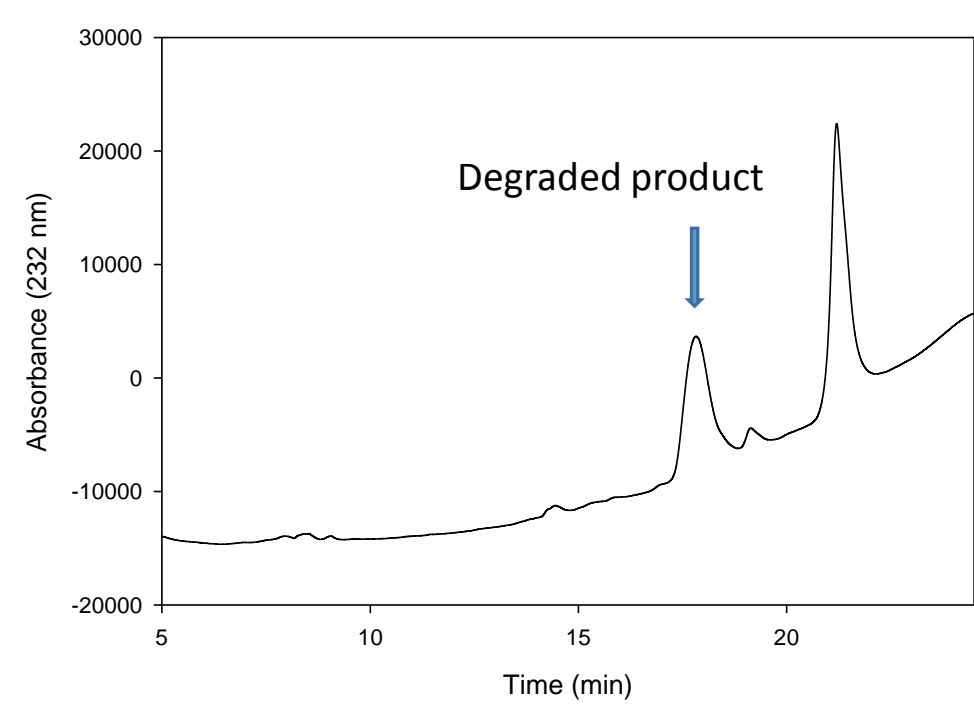

3_NH4CO3_36h

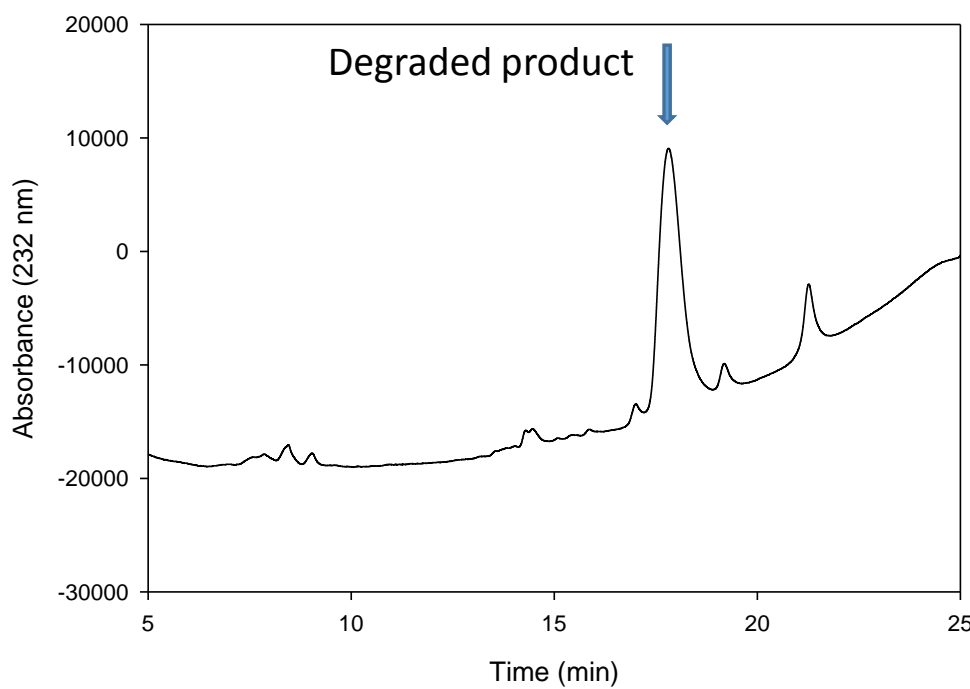

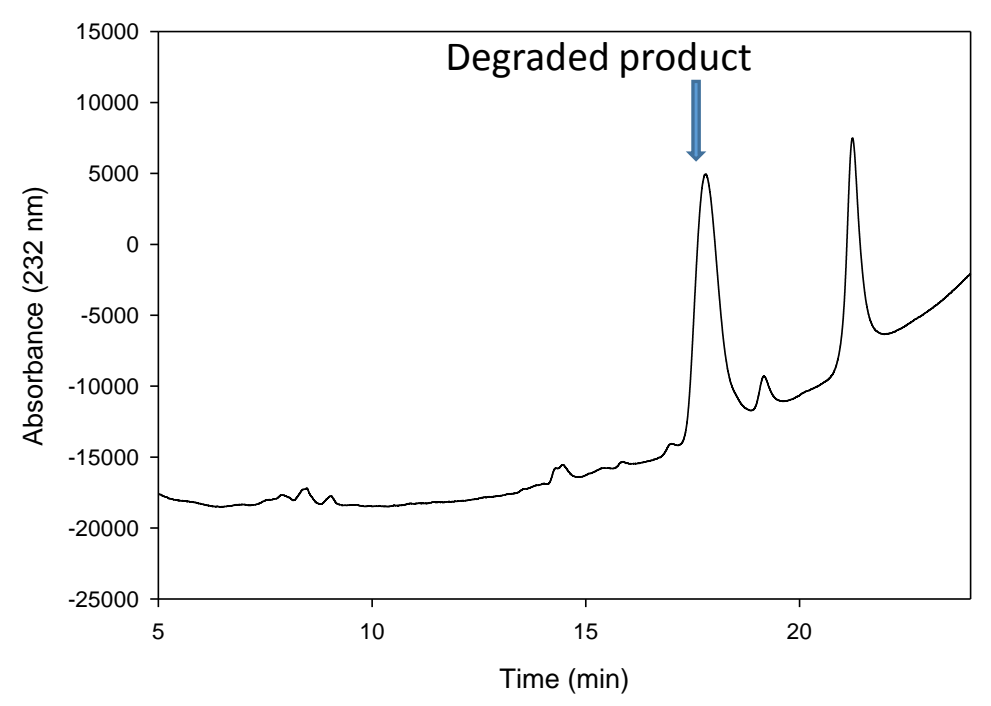

3_NH4CO3_48h

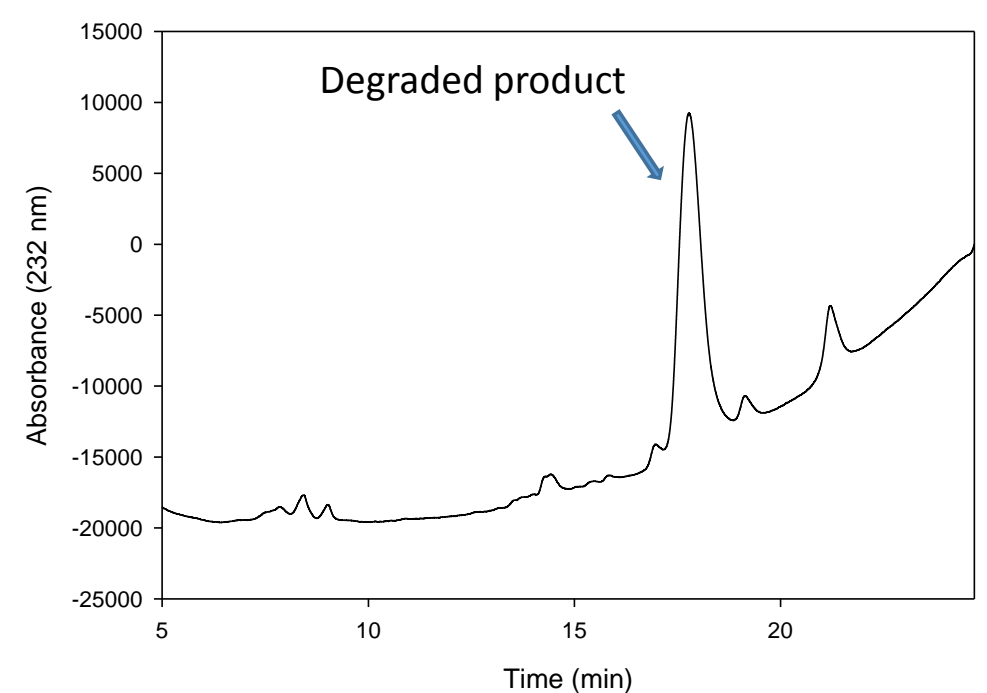

Supplementary Fig S10. HPLC chromatograms of compound 3 in $0.1 \mathrm{M} \mathrm{NH}_{4} \mathrm{HCO}_{3}$ buffer over time. 

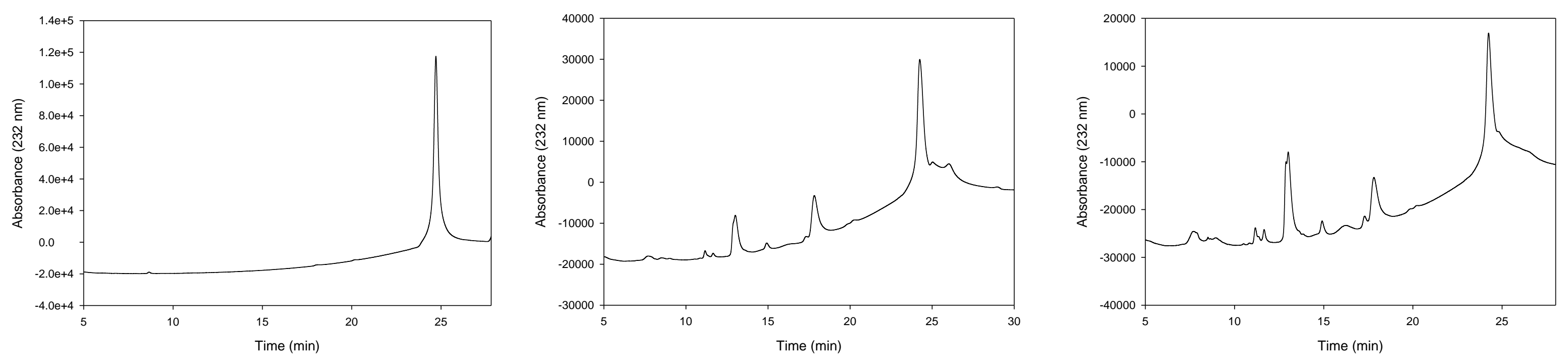

4_NH4CO3_36h

\section{Compound 4}

\section{$\Delta$ UA-GIcNS3S6S}
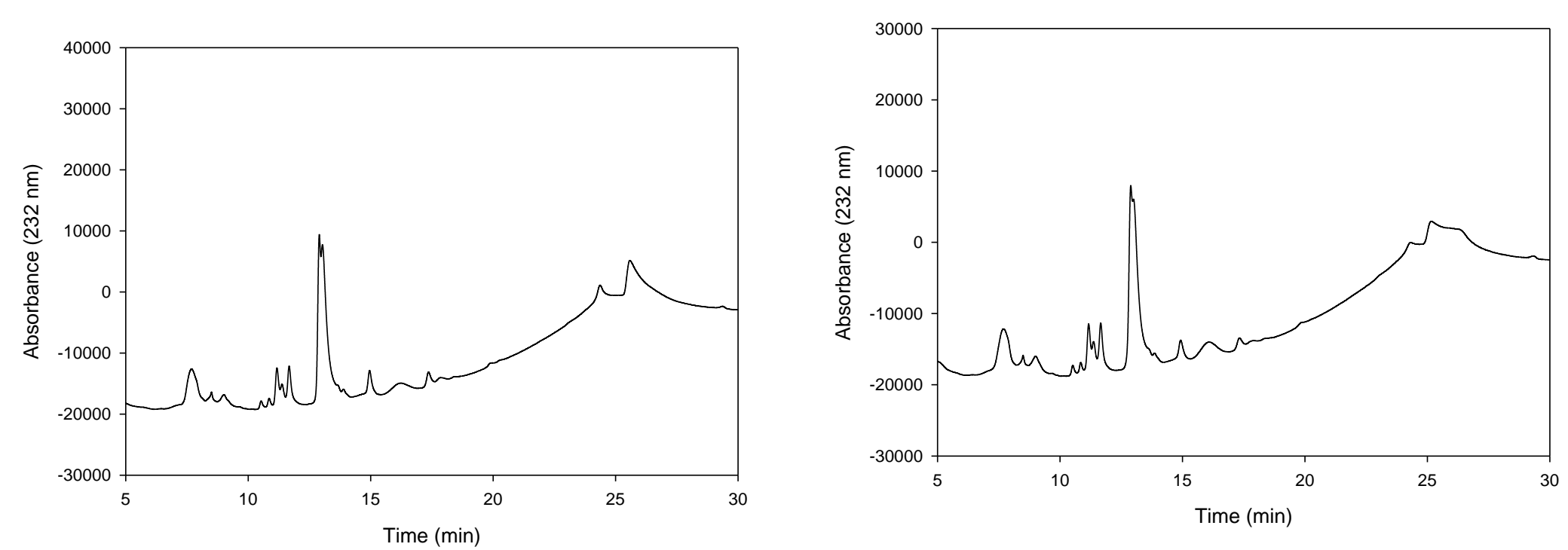

Supplementary Fig S11. HPLC chromatograms of compound 4 in $0.1 \mathrm{M} \mathrm{NH}_{4} \mathrm{HCO}_{3}$ buffer over time . 
NS6S_control_48h

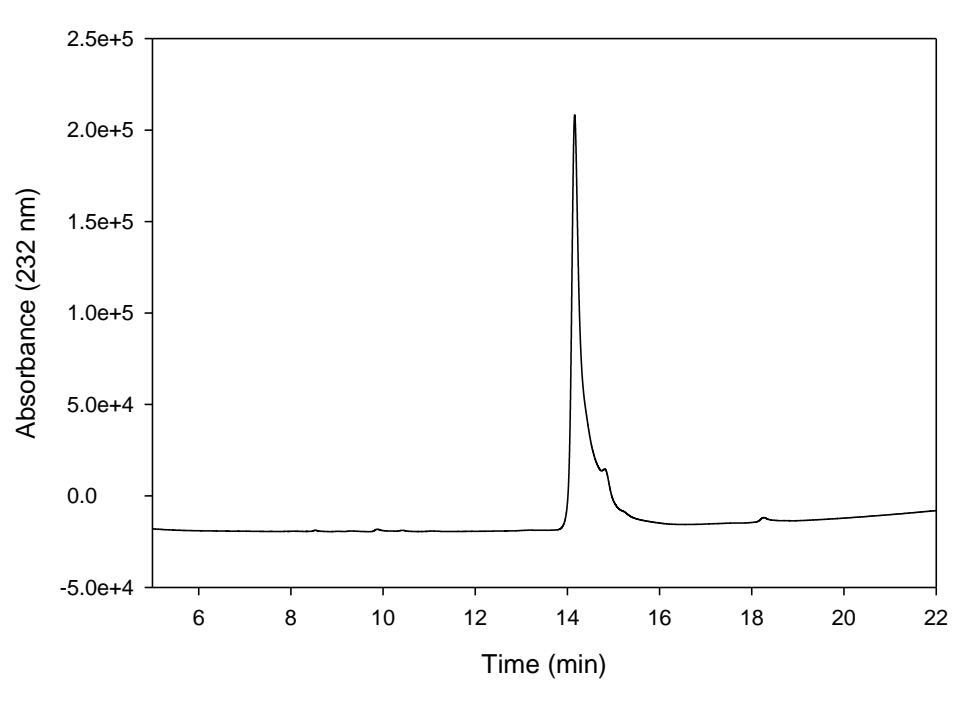

NS6S NH4CO3 $48 \mathrm{~h}$

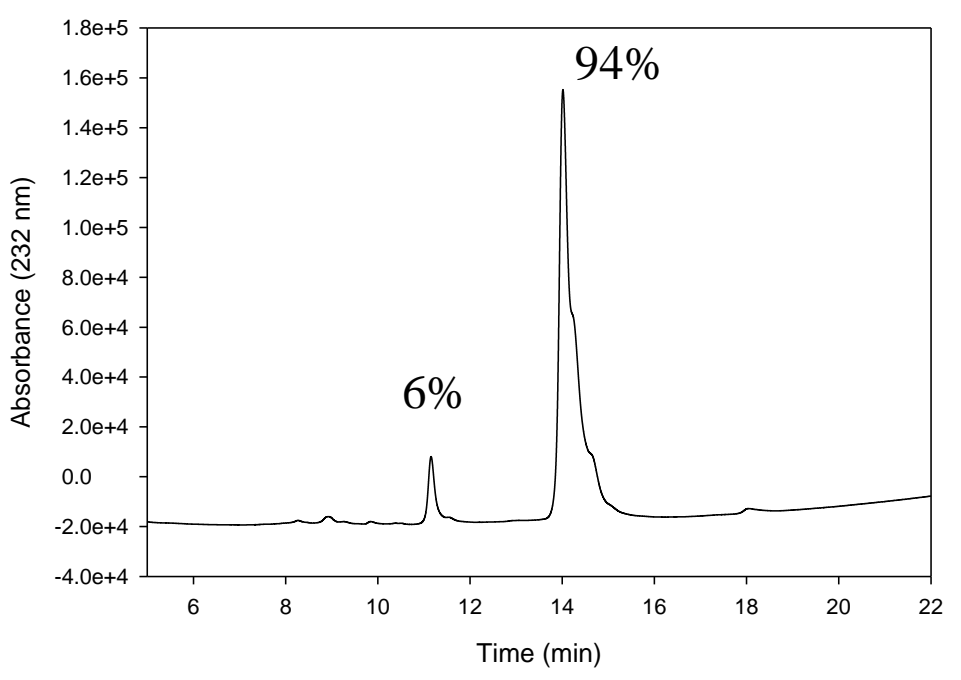

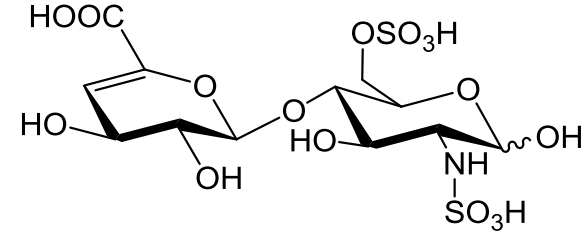

$\Delta$ UA-GlcNS6S

Supplementary Fig S12. HPLC chromatograms of $\triangle \mathrm{UA}$-GlcNS6S disaccharide with or without incubation in $0.1 \mathrm{M} \mathrm{NH}_{4} \mathrm{HCO}_{3}$ buffer for 48 hours. 
Compound 1

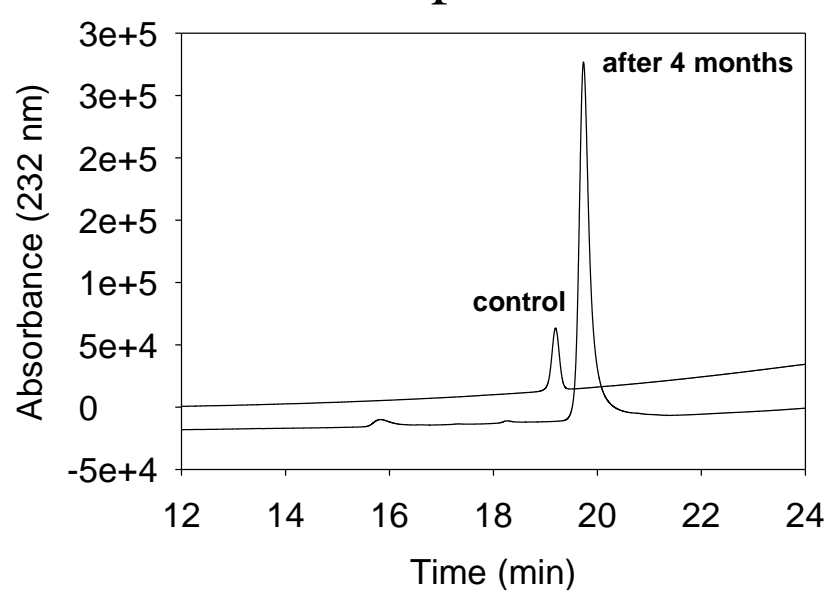

Compound $\mathbf{3}$

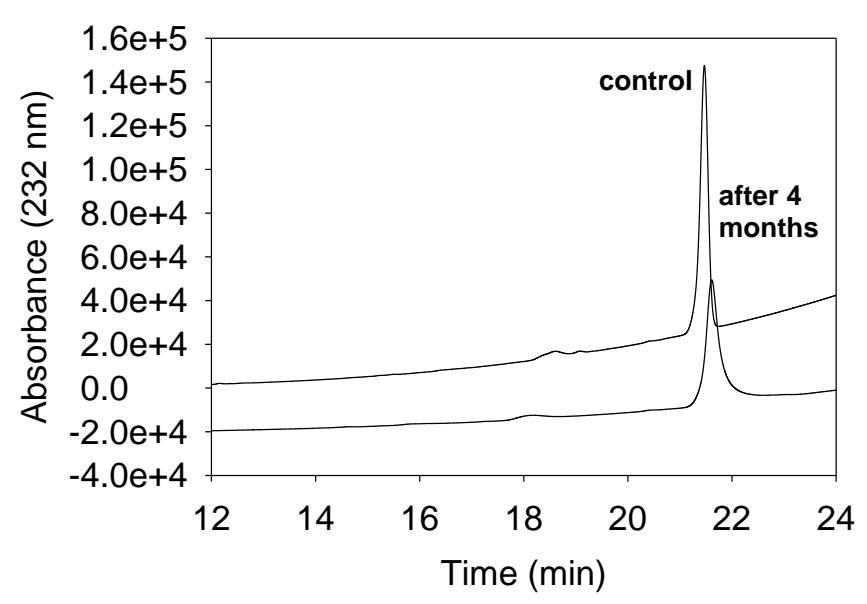

\section{Compound 2}

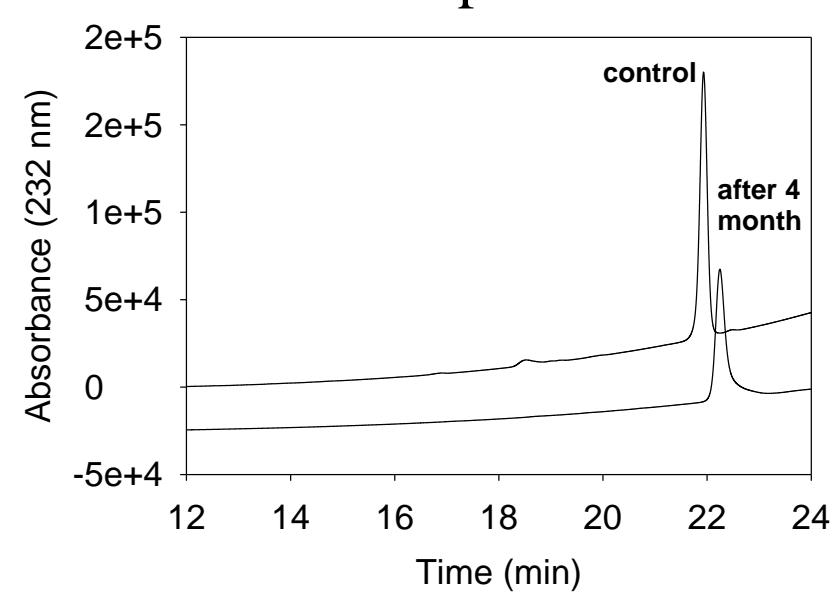

Compound 4

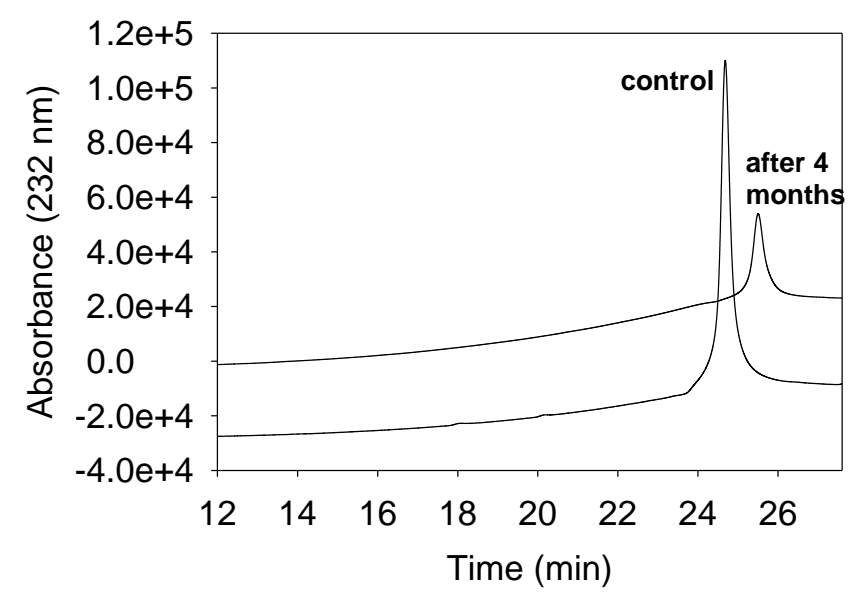

Supplementary Fig S13. Stability data of compound 1-4 before and after 4 months 

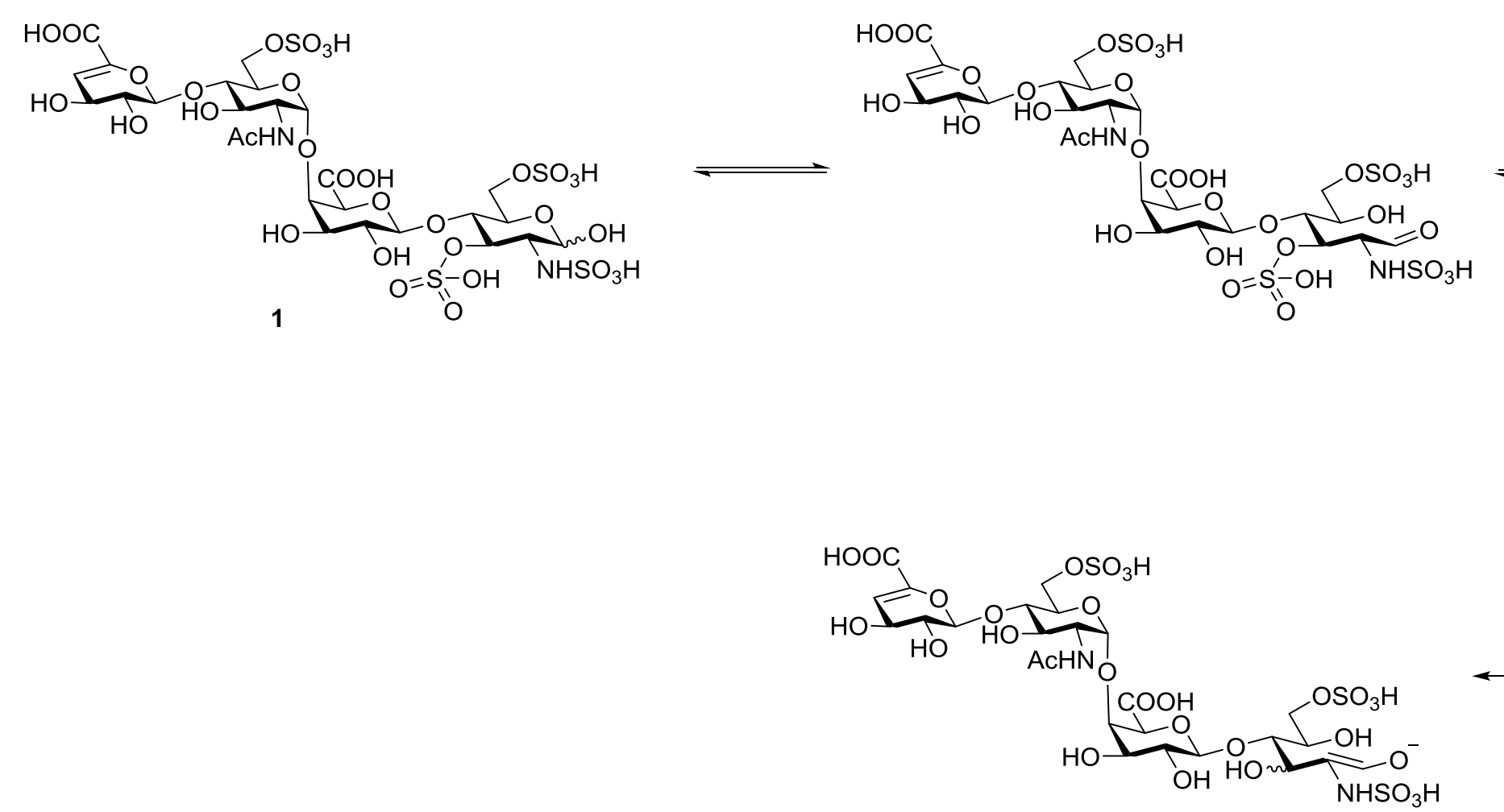

desulfated tetrasaccharide
管
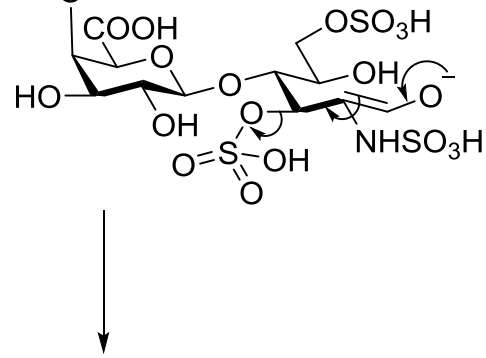

HOCOHOH

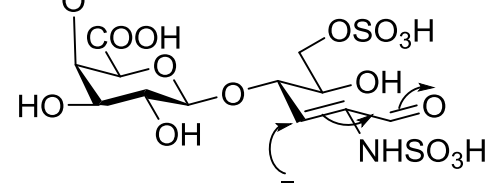

$\overline{\mathrm{OH}}$
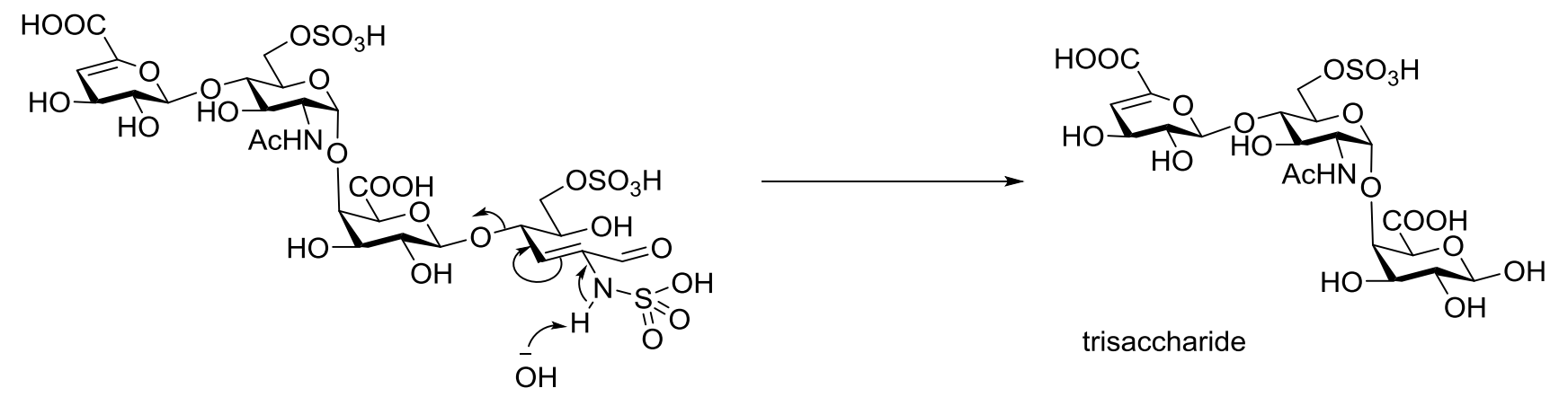

Supplementary Fig S14. Mechanism for the degradation reaction for compound 1 under basic conditions. The mechanism was proposed based on the reference 30. 